\title{
Effects of behavioral activation program without psychotropic medication treatment for depression in late adolescence: case report
}

This article was published in the following Dove Press journal:

Neuropsychiatric Disease and Treatment

\author{
Koki Takagaki ${ }^{\prime}$ \\ Yasumasa Okamoto' \\ Ran Jinnin' \\ Satoshi Yokoyama' \\ Atsuo Yoshino' \\ Fumi Kagawa' \\ Yuri Okamoto ${ }^{2}$ \\ Yoshie Miyake ${ }^{2}$ \\ Shigeto Yamawaki' \\ 'Department of Psychiatry and \\ Neurosciences, Hiroshima University, \\ Hiroshima, Japan; ${ }^{2}$ Health Service \\ Center, Hiroshima University, \\ Hiroshima, Japan
}

\begin{abstract}
Background: A Japanese study revealed that $20.7 \%$ of first-year undergraduate students had a major depressive episode during the previous 12 months: first-year undergraduate students with depression need early support. Reportedly, antidepressant medication use during adolescence is associated with modestly increased risk of suicidality. This case study of a late-adolescent woman with depression illustrates the effects of behavioral activation without psychotropic medication.
\end{abstract}

Case presentation: A first-year undergraduate student was diagnosed as having major depressive disorder. From earlier studies, we developed a behavioral activation program for late-adolescent people with major depressive disorder. Behavioral activation administered in 10 weekly 60 -minute sessions decreased depressive symptoms, avoidant behaviors, and rumination. Moreover, the Beck Depression Inventory, second version score was 1 at 1-year follow-up.

Conclusion: Results of this case study show that behavioral activation is effective without psychotropic medication. Future studies of large samples must be conducted to assess the effectiveness of behavioral activation without psychotropic medication for depression in late adolescence.

Keywords: avoidant behavior, behavioral activation without psychotropic medication, major depressive symptoms, rumination

\section{Introduction}

Reportedly, about $15 \%-20 \%$ of the university students are diagnosed as having depression. ${ }^{1}$ In Japan, $20.7 \%$ of the first-year undergraduate students reported that they had a major depressive episode during the previous 12 months. ${ }^{2}$ An earlier report described a relation between depression and suicide among university students. ${ }^{3}$ Therefore, early support is regarded as necessary for first-year undergraduate students with depression.

Cognitive behavioral therapy is an effective intervention for depression. ${ }^{4} \mathrm{~A}$ recent study described that behavioral activation is as effective and more cost-effective for depression than cognitive behavioral therapy. ${ }^{5}$ Another study found no significant difference in depressive symptoms when depression was treated with behavioral activation or antidepressant medication. ${ }^{6}$ Reportedly, the use of antidepressant medication for adolescent depression is associated with a modestly increased risk of suicidality. ${ }^{7}$ Therefore, behavioral activation might be a favored mode of early support for depression in late adolescence. Nevertheless, few studies have examined whether behavioral activation for late-adolescent person with depression is effective without psychotropic medication. No behavioral activation program for depression in late
Correspondence: Yasumasa Okamoto Department of Psychiatry and Neurosciences, Hiroshima University, I-2-3 Kasumi, Minami-ku, Hiroshima, 734-855I, Japan

Tel +8I 822575208

Fax +8I 822575209

Email oy@hiroshima-u.ac.jp 
adolescence was identified in Japan. Therefore, behavioral activation programs for depression in late adolescence were adopted based on earlier or existing programs of other kinds. This report presents the effects of a behavioral activation program without psychotropic medication to treat a lateadolescent woman with depression.

\section{Case presentation}

The participant provided written informed consent to having her case details published.

The participant was a first-year undergraduate student (18-19-year-old Japanese woman). The Beck Depression Inventory, second version (BDI-II) is administered yearly to all first-year students of the university as a part of their health examination, which is conducted at the Health Service Center. They are notified of the need for a medical consultation from the Health Service Center if they have a high score on BDI-II in the health examination. She lived by herself after enrolling at the university. She usually had a depressed mood and felt discouraged. Later, she felt fatigued and convinced of her own worthlessness. She received a medical examination by a psychiatrist at the Health Service Center. She met the criteria for a diagnosis of major depressive disorder according to the Diagnostic and Statistical Manual of Mental Disorders, fourth edition, text revision criteria. ${ }^{8}$ The participant had never developed a major depressive episode before entering the university and had never received treatment before. Therefore, she never took psychotropic drugs. A report of one earlier study described that the use of antidepressant medication by adolescents is associated with a modestly increased risk of suicidality. ${ }^{7}$ Although she was able to live a university life as usual, the participant did not receive medication or psychotherapy for treatment at that time. A psychiatrist recommended psychotherapy to the first author. She consented to undergo psychotherapy.

For pretreatment assessments, we used the BDI-II, ${ }^{9,10}$ the Behavioral Activation for Depression Scale (BADS), ${ }^{11,12}$ and the Environmental Reward Observation Scale (EROS). ${ }^{13,14}$ Results of pretreatment assessments were the following: BDI-II=31, BADS-Activation $(\mathrm{AC})=8$, BADS-Avoidance/ Rumination $(A R)=35$, BADS-Work/School Impairment $(\mathrm{WS})=4$, BADS-Social Impairment $(\mathrm{SI})=30$, BADS-total=47, and $\mathrm{EROS}=17$. Assessment results indicated behavioral characteristics as low frequency of activity and high frequency of avoidant behavior and rumination. Moreover, she felt a lack of a sense of pleasure or mastery in regular life. It is important to increase feelings of a sense of pleasure or mastery and to decrease avoidant behaviors and ruminations to decrease depressive symptoms. ${ }^{15,16}$ Therefore, based on earlier studies, ${ }^{15-17}$ we developed a behavioral activation program for late-adolescent people with major depressive disorder. The first author (KT) administered behavioral activation to her with a program consisting of 10 weekly 60 -minute sessions. In the first phase (sessions 1-5), the program emphasized increased activities that provided a sense of pleasure or mastery. The second phase (sessions 5-10) emphasized modification of avoidant behaviors and ruminations to alternative behaviors. The program included psychoeducation about depression and behavioral activation (Session 1), assessing value, long-term and short-term goals (sessions 1, 2), developing activity monitoring (Session 2), developing a behavioral hierarchy of about ten tasks providing a sense of pleasure or mastery (Session 2), behavioral experiments and increasing scheduled activities (sessions 2-5), psychoeducation about avoidant behavior and rumination (sessions 5, 6), developing a behavioral hierarchy of ten tasks of avoidant behaviors and rumination (Session 6), and modifying avoidant behaviors and rumination to alternative behaviors (sessions 6-9). Session 10 included review of behavioral activation and creation of a plan for self-management for high-stress situations.

During sessions 1-2, the therapist provided psychoeducation related to depression and behavioral activation. At the beginning of treatment, we discussed values and goals to increase activities that provided a sense of pleasure or mastery and modified avoidant behaviors to alternative behaviors based on her values. She selected three value domains: 1) friendships, 2) work/career, and 3) recreation/ leisure. Then she identified her values in the three domains: 1) she offered her own conversation topics and easily talked with other people; 2) she studied foreign languages voluntarily; and 3) she learned more about the world of art. Next, we identified her goals to the end point of treatment as explained below: 1) she will express her opinions in conversations with friends; 2) she will study foreign languages every day when not attending lectures; and 3) she will go to the art museum to study. She developed a behavioral hierarchy of about eleven tasks to increase activities that provide a sense of pleasure or mastery (from less difficult to very difficult: 1) look at the stars at night, 2) watch a DVD, 3) take a walk in the neighborhood, 4) read books, 5) learn German and English words, 6) study at the library on a day off, 7) relax in the park, 8) review it by the next lecture, 9) go to the art museum, 10) go to a secondhand bookstore, and 11) express opinions in conversations with friends). Her goal was to express opinions in conversations with friends in the friendship domain. Consequently, 
this is an activity to obtain social skills through conversations with friends. Regarding her work and career, her goal was that she will study foreign languages every day when not attending lectures. Furthermore, she selected three activities (learn German and English words, study at the library on a day off, review it by the next lecture). Regarding recreation and leisure, her goal was to go to the art museum to study. She selected one activity (go to the art museum). The other six activities are not related directly to the goal after treatment, but were selected as activities to increase her sense of pleasure or mastery in everyday life. During sessions $2-5$, she conducted behavioral experiments from a list of behavioral hierarchy to increase the behavioral repertoire. After behavioral experiments, she monitored the results of behavioral experiments in terms of what happened and what she felt. During sessions 3-6, we conducted a review of the behavioral experiment. She continued to do activities to increase her behavioral repertoire, which provided a sense of pleasure or mastery if she understood that activities are useful to elicit a change of mood. If she was unable to conduct a behavioral experiment, we conducted a review of the behavioral experiment to identify barriers. Next, we discussed means of surmounting the barriers. As the point of session 6 , she engaged in many activities that provided a sense of pleasure or mastery. For example, she went to the park to relax in one behavioral experiment. Because she had never gone to a park alone to relax, when she went to the park, she did not anticipate a good relaxing effect. However, when she was sitting down on the bench, she noticed that she felt calmer than before. Furthermore, it occurred to her that she wanted to find places where she felt calmer.

In the secondary phase (sessions 5-10), we emphasized modification of avoidant behaviors and ruminations to alternative behaviors based on values and goals. One of her values was to offer her own conversation topics and to converse easily with other people. Furthermore, her goal to the end point of treatment was to express her opinions in conversation. Nevertheless, she felt it difficult to achieve the goal. First, she and the therapist conducted functional analysis related to a situation of the avoidant behavior using Trigger-Response-Avoidance Pattern (TRAP). ${ }^{15,16}$ When she discussed matters with friends in class, she looked away from friends and did not express her opinions in discussions because she usually felt nervous about expressing her opinions in this situation. Although she felt at ease with short-term results, she was unable to resolve her difficulties with long-term results. Next, we discussed strategies to modify her avoidant behaviors to alternative behaviors based on values and goals using Trigger-Response-Alternative
Coping (TRAC). ${ }^{15,16} \mathrm{We}$ brainstormed strategies to assign simple to more complex tasks in a stepwise fashion. Additionally, we designed assignments such that early success was guaranteed. The first step assignment was to raise her hand at least once in a discussion if she had an opinion. As a result of the alternative behavior, although she felt tension and fatigue, she felt confident about expressing her opinion. Furthermore, she said that she might be able to speak up in class discussions. Subsequently, the frequency of expressing her opinions increased. She began to participate actively in some university events. As the target of the next step assignment, she usually felt tired, and felt worthless, ruminating about past failures. The therapist conducted functional analysis to examine rumination using TRAP. For example, she ruminated about past failures on the way to and from the university because she had trouble getting along with people. One alternative behavior that she can learn to substitute for ruminating is practicing attention to her own experience. ${ }^{16}$ She and the therapist discussed strategies to reduce rumination and to activate alternative behaviors based on values and goals. Among her values, she selected one value in the domain of friendships. Ruminating about past failures of relationships was regarded as having a negative effect on building friendships. As alternative behaviors, when she ruminated about past failures on the way to and from the university, she practiced devoting attention to the surrounding landscape to relieve the focus on her own experiences. At the beginning of practice, although she started to devote attention to the surrounding landscape, her ruminations did not diminish. However, after repeated practice, she was able to reduce ruminations. Eventually, she decreased the frequency of rumination and came to address rumination.

In the final session, we reviewed goals until the end of treatment. She conducted the task against all goals. She said that she became able to state her opinions to a greater degree than before intervention and increased the time for learning foreign languages every day. Moreover, she went to the art museum to learn about the world of art. She became able to understand various aspects of art and wanted to learn more.

Post-assessment showed that the score of depressive symptoms had decreased (BDI-II $=6$ ), and that scores of behavioral characteristics had improved (BADS-AC $=17$, BADS$\mathrm{AR}=21, \mathrm{BADS}-\mathrm{WS}=3$, BADS-SI=19, BADS-total $=82$, $\mathrm{EROS}=23$ ). After completing the intervention, the BDI-II was measured to examine the change of depressive symptoms during 1-year follow-up. The results of follow-up demonstrated that the BDI-II score 1 year later was 1 (Figure 1). 


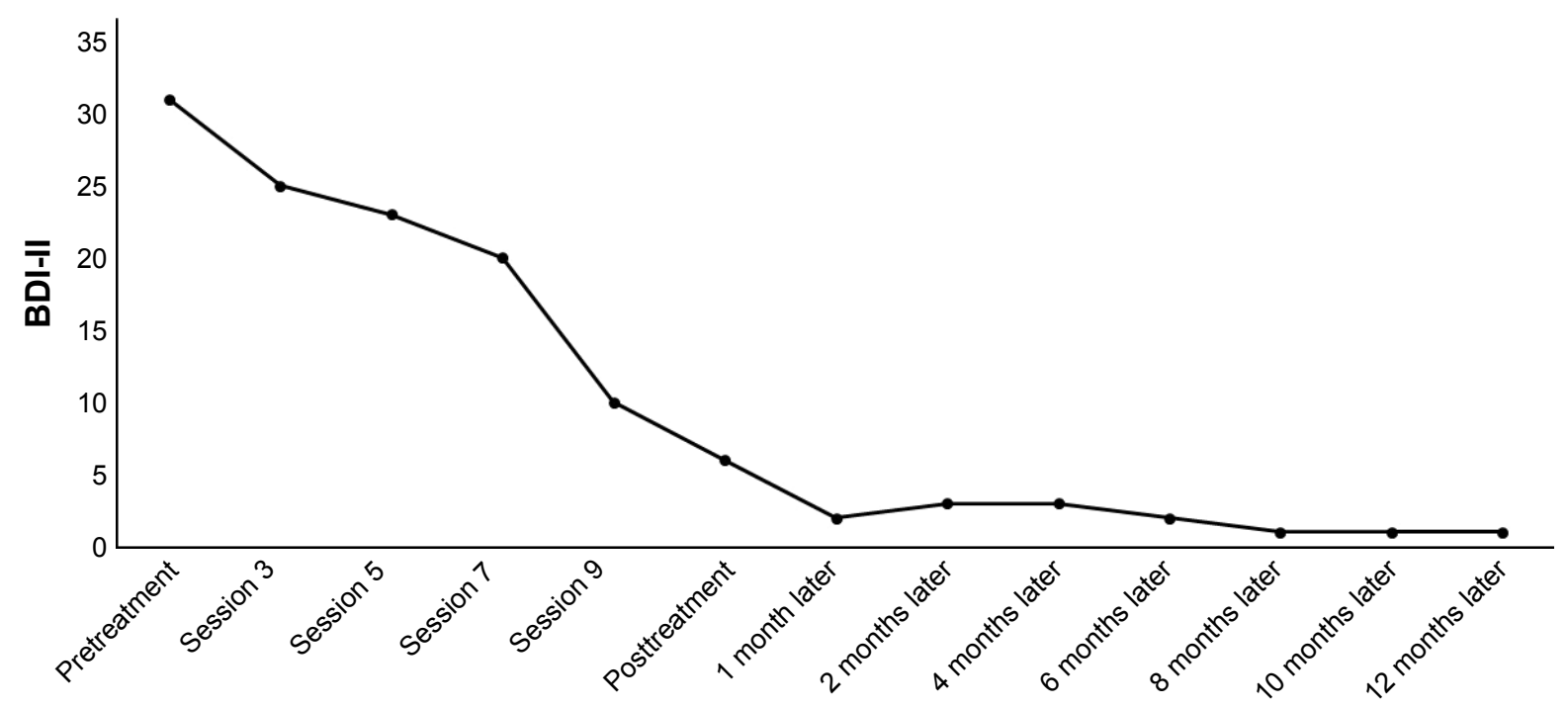

Figure I Change of BDI-II score.

Abbreviation: BDI-II, Beck Depression Inventory, second version.

In an assessment conducted 1 year later, scores of behavioral characteristics had improved: BADS-AC $=21$, BADS$\mathrm{AR}=18, \mathrm{BADS}-\mathrm{WS}=0$, BADS-SI=4, BADS-total=107, and EROS $=25$. We confirmed at 1-year follow-up whether she had received other treatment during the study period. She received no other treatment during the study period.

\section{Discussion}

The present case report describes an attempt at behavioral activation for a late-adolescent person with depression without using psychotropic medication treatment. After conducting behavioral activation in 10 weekly 60-minute sessions, the scores of BDI-II, BADS-AR, BADS-WS, and BADS-SI decreased from pretreatment to posttreatment. These results suggest that her depressive symptoms, avoidant behaviors, ruminations, and dysfunctions improved. Moreover, the scores of BADS-AC and EROS increased from pretreatment to posttreatment, which suggests that the frequency of activities provided a sense of pleasure or mastery and that her response-contingent positive reinforcement increased in regular life. Furthermore, the BDI-II score of 1 at 1-year follow-up indicates that improvement of depressive symptoms was maintained after the end of the behavioral activation program. According to the BDI-II cut-off scores provided by Beck et al, ${ }^{9}$ a 0-13 score was the minimal range, 14-19 score was the mild range, 20-28 score was the moderate range, and 29-63 was the severe range. Although the participant's score was in the severe range in pre-assessment (BDI-II=31), her mood state improved to the minimal range at post-assessment $(\mathrm{BDI}-\mathrm{II}=6)$ and 1-year follow-up (BDI-II=1). Therefore, this result suggests that depressive symptoms have decreased to a clinically significant degree.

Our behavioral activation program included two phases. The first phase from Session 1 through Session 5 emphasized increase in activities that provided a sense of pleasure or mastery. The second phase emphasized modification of avoidant behaviors and ruminations to alternative behaviors from Session 5 through Session 10. Based on BDI-II scores results from pretreatment to posttreatment, a more drastic change was achieved in the second phase (BDI-II score change of 23-6) than in the first phase (BDI-II score change of 31-23). An earlier report described that first-year undergraduate students with depression are characterized by a high frequency of avoidance and low access to environmental rewards. ${ }^{18}$ In addition, simple behavioral activation intervention that increases activities providing a sense of pleasure or mastery has been recommended during early treatment. ${ }^{19}$ In this case, although simple behavioral activation intervention was effective, simple behavioral activation alone might not have been sufficient. Avoidance processes contribute to depression by limiting exposure to positive experiences and sources of positive reinforcement and by increasing the likelihood of negative outcomes and experiences. ${ }^{20}$ The score of avoidant behavior (BADS-AR) in pretreatment was higher than in the earlier study. ${ }^{18}$ She avoided expressing her own opinions in conversation and spent much time ruminating. Through functional analysis using TRAP and TRAC against avoidant behaviors and ruminations, she realized that avoidant behaviors and ruminations engender bad results for her. We discussed strategies to stop ruminations and to activate 
alternative behaviors based on her values and goals. Although her rumination did not stop at the beginning of practice, she practiced repeatedly. An earlier report of the literature described that values might function as reinforcement for value-relevant behavior. ${ }^{21}$ Values might be used to motivate and sustain activation behaviors when it is expected that reinforcers for activation behavior will not occur immediately. ${ }^{19}$ She selected alternative behaviors based on her values. Therefore, she was able to use alternative behaviors repeatedly from rumination. Avoidant behaviors and ruminations were a core difficulty for her. Results suggest that depressive symptoms were decreased by understanding the mechanisms and by adopting alternative behaviors through functional analysis. ${ }^{15,16}$ In fact, she has reported that she is living a more enjoyable life than she had lived before treatment. Results of follow-up indicate that the effects of behavioral activation had persisted through 1 year. Results suggest that she continued to do what she learned in the behavioral activation program.

The participant had never developed a major depressive episode before entering university. In this case, the new environment might have caused or exacerbated depression after she entered university. Because this intervention emphasized increased activities that provided a sense of pleasure or mastery and because it modified avoidant behaviors and ruminations, increased coping and adjustment might have contributed to the decrease she showed in depressive symptoms. Moreover, participants attended intervention without absence. She might have understood the need for intervention through psychoeducation and might have, therefore, been very motivated to participate. Psychoeducation might have contributed to decreasing her depressive symptoms. The willingness and insight of the participants themselves might have affected the intervention.

\section{Conclusion}

A report of an earlier study described that the use of antidepressant medication by adolescents is associated with a modestly increased risk of suicidality. ${ }^{7}$ This case report presents the important finding that a behavioral activation program was effective without psychotropic medication. Nevertheless, this was a case study. A future study of large sample must be done to assess the effectiveness of behavioral activation without medication for depression in late adolescence.

\section{Acknowledgment}

This study was supported by Grants-in-Aid for Scientific Research on Innovative Areas from JSPS: grant numbers $16 \mathrm{H} 06395$ and $16 \mathrm{H} 06399$.

\section{Disclosure}

The authors report no conflicts of interest in this work.

\section{References}

1. Benton SA, Robertson JM, Tseng W-C, Newton FB, Benton SL. Changes in counseling center client problems across 13 years. Prof Psychol. 2003;34(1):66-72.

2. Tomoda A, Mori K, Kimura M, Takahashi T, Kitamura T. One-year prevalence and incidence of depression among first-year university students in Japan: a preliminary study. Psychiatry Clin Neurosci. 2000; 54(5):583-588.

3. Furr SR, Westefeld JS, Mcconnell GN, Jenkins JM. Suicide and depression among college students: a decade later. Prof Psychol. 2001;32(1): $97-100$.

4. Tolin DF. Is cognitive-behavioral therapy more effective than other therapies? A meta-analytic review. Clin Psychol Rev. 2010;30(6): 710-720.

5. Richards DA, Ekers D, Mcmillan D, et al. Cost and Outcome of Behavioural Activation versus Cognitive Behavioural Therapy for Depression (COBRA): a randomised, controlled, non-inferiority trial. Lancet. 2016;388(10047):871-880.

6. Dimidjian S, Hollon SD, Dobson KS, et al. Randomized trial of behavioral activation, cognitive therapy, and antidepressant medication in the acute treatment of adults with major depression. J Consult Clin Psychol. 2001;74(4):658-670.

7. Hammad TA, Laughren T, Racoosin J. Suicidality in pediatric patients treated with antidepressant drugs. Arch Gen Psychiatry. 2006;63(3): 332-339.

8. American Psychiatric Association. Diagnostic and Statistical Manual of Mental Disorder. 4th ed. text revision (DSM-IV-TR). Washington: American Psychiatric Association; 2000.

9. Beck AT, Steer RA, Brown GK. Beck Depression Inventory: Manual. 2nd ed. Texas: The Psychological Corp.; 1996.

10. Kojima M, Furukawa T. Japanese Version of the Beck Depression Inventory. 2nd ed. Tokyo: Nippon-Hyoron-sha Co.; 2003.

11. Kanter JW, Mulick PS, Busch AM, Berlin KS, Martell CR. The Behavioral Activation for Depression Scale (BADS): psychometric properties and factor structure. J Psychopathol Behav Assess. 2007;29(3): 191-202.

12. Takagaki K, Okajima I, Kunisato Y, et al. Development and validation of the Japanese version of the Behavioral Activation for Depression Scale (BADS). Arch Psychiatry Diagn Clin Eval. 2013;6:76-85.

13. Armento ME, Hopko DR. The Environmental Reward Observation Scale (EROS): development, validity, and reliability. Behav Ther. 2007; 38(2):107-119.

14. Kunisato Y, Takagaki K, Okajima I, et al. Development of Japanese version of Environmental Reward Observation Scale (EROS). Jpn J Behav Ther. 2011;37:21-31.

15. Addis M, Martell C. Overcoming Depression One Step at a Time: The New Behavioral Activation Approach to Getting Your Life Back. Oakland, CA: New Harbinger Publications; 2004.

16. Martell CR, Addis ME, Jacobson NS. Depression in Context: Strategies for Guided Action. New York: W. W. Norton \& Company; 2001.

17. Takagaki K, Okamoto Y, Jinnin R, et al. Behavioral activation for late adolescents with subthreshold depression: a randomized controlled trial. Eur Child Adolesc Psychiatry. 2016;25(11):1171-1182.

18. Takagaki K, Okamoto Y, Jinnin R, et al. Behavioral characteristics of subthreshold depression. J Affect Disord. 2014;168:472-475.

19. Kanter JW, Busch AM, Rusch LC. Behavioral Activation: Distinctive Features. New York: Routledge; 2009.

20. Trew JL. Exploring the roles of approach and avoidance in depression: an integrative model. Clin Psychol Rev. 2011;31(7):1156-1168.

21. Kanter JW, Manos RC, Bowe WM, Baruch DE, Busch AM, Rusch LC What is behavioral activation? A review of the empirical literature. Clin Psychol Rev. 2010;30(6):608-620. 


\section{Publish your work in this journal}

Neuropsychiatric Disease and Treatment is an international, peerreviewed journal of clinical therapeutics and pharmacology focusing on concise rapid reporting of clinical or pre-clinical studies on a range of neuropsychiatric and neurological disorders. This journal is indexed on PubMed Central, the 'PsycINFO' database and CAS, and is the official journal of The International Neuropsychiatric Association (INA). The manuscript management system is completely online and includes a very quick and fair peer-review system, which is all easy to use. Visit http://www.dovepress.com/testimonials.php to read real quotes from published authors.

\footnotetext{
Submit your manuscript here: http://www.dovepress.com/neuropsychiatric-disease-and-treatment-journal
} 